\title{
Christian Heinze
}

\section{Schadensersatz im Unionsprivatrecht}

Eine Studie zu Effektivität und Durchsetzung des Europäischen Privatrechts am Beispiel des Haftungsrechts

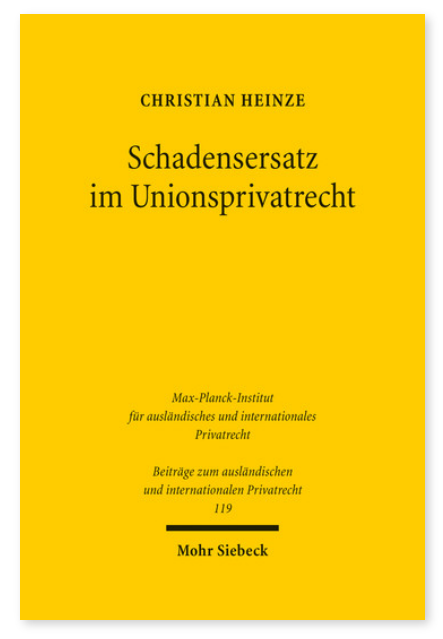

2017. XXV, 700 Seiten. BtrIPR 119

ISBN 978-3-16-154202-2

DOI 10.1628/978-3-16-154202-2

eBook PDF $114,00 €$

ISBN 978-3-16-154201-5

Leinen $114,00 €$
»Wo Recht ist, da ist auch Abhilfe« - dies gilt nicht ohne weiteres für das Privatrecht der Europäischen Union, das die Folgen einer Verletzung europäisch fundierter Rechte im Regelfall den nationalen Regeln überlässt. Im Interesse der wirksamen Durchsetzung des Unionsrechts haben allerdings Gerichtshof und europäischer Gesetzgeber in jüngerer Zeit Vorgaben auch für die Rechtsdurchsetzung durch die nationalen Gerichte formuliert. Ausgehend von drei unterschiedlichen

Einwirkungsformen des Unionsrechts, nämlich der Rahmensetzung durch den Effektivitätsgrundsatz, der Rechtsangleichung durch Richtlinien und der Rechtsvereinheitlichung durch Verordnungen untersucht Christian Heinze am Beispiel von zehn Sachfragen des Schadensersatzes die Einflüsse des Unionsrechts auf das nationale Haftungsrecht.

Christian Heinze ist Inhaber des Lehrstuhls für Bürgerliches Recht, Handels- und Wirtschaftsrecht, Europarecht und Rechtsvergleichung an der Universität Heidelberg.

Jetzt bestellen:

https://mohrsiebeck.com/buch/schadensersatz-im-unionsprivatrecht-9783161542022?no_cache=1

order@mohrsiebeck.com

Telefon: +49 (0)7071-923-17

Telefax: +49(0)7071-51104 